\title{
Investigation of compatibilization effects of SEBS-g-MA on polystyrene/polyethylene blend with a novel separation method in melted state
}

\author{
Károly Dobrovszky, Ferenc Ronkay* \\ Department of Polymer Engineering, Faculty of Mechanical Engineering, Budapest \\ University of Technology and Economics, \\ H-1111 Budapest, Müegyetem rkp. 3, Hungary \\ * Corresponding author. Tel.: +36 1 463-2462; Fax.: +36 1 463-1527 \\ E-mail address: ronkay@pt.bme.hu (F. Ronkay).
}

\begin{abstract}
:
Preparing polymer blends is an effective way to tailor the good properties of plastics but the most commonly used polymers are incompatible with each other. Therefore, to reduce the interfacial tension and to achieve finer and stable morphology, a suitable copolymer or compatibilizer has to be added to blends in order to establish new interactions between the phases. However, it is difficult to determine the required amount of compatibilizers in polymer blends. As an outcome of the present research a novel separation method was developed, where the blends are investigated in melted state, utilising centrifugal force to determine the adequacy of compatibilizers. The effectiveness of styrene/ethylene/butylene/styrene block copolymer grafted with maleic anhydride (SEBS-g-MA) was verified by blending two immiscible plastics: polystyrene (PS) and high density polyethylene (HDPE). FTIR measurements were carried out to support the results of optical microscopy regarding the purity of separation. Comparing the results of morphology, rheology and mechanical properties with the novel separation method, it seems that investigation of compatibilization effect in a melted state would be suitable for predicting the adequacy of compatibilizer in blend. The minimum required amount of compatibilizer was also detectable, wherein the stress-strain curves begins to change significantly and the impact properties starting to improve in PS/HDPE blends.
\end{abstract}

Keywords: compatibilization; polymer separation; polymer blend; centrifugal force; polymers in melted state.

Acknowledgements: This research was realized in the framework of TÁMOP 4.2.4. A/1-111-2012-0001 "National Excellence Program - Elaborating and operating an inland student and researcher personal support system". The project was subsidized by the European Union and co-financed by the European Social Fund. The infrastructure of the research project was supported by the Hungarian Scientific Research Fund (OTKA K109224). 


\section{Introduction}

The interest of industrial and academic area is growing for polymer blends, because the good physical and mechanical properties of plastics can be tailored this way [1,2]. In most cases, polymers are incompatible with each other because of their high molecular weight $[3,4]$ and for thermodynamic reasons [5,6]. In these blends usually an immiscible, heterogeneous morphological structure forms that causes low mechanical properties due to the poor interfacial interaction of the components.

In case of preparing polymer blends, the final morphology strongly depends on droplet breakup and coalescence processes during shear flow [7]. These two forces both dominate under transient condition, and their balance in steady state was described by Taylor's theory of Capillary number [8,9]. In case, when breakup occurs the capillary number exceeds a critical value. However, when the average droplet size is smaller than the steady-state size, coalescence dominates $[10,11]$. Nowadays, the key point is to reduce the interfacial tension achieving more stable, reproducible morphology in order to improve the tensile and impact properties of blends $[12,13]$. Finer blend morphology can be achieved with a suitable copolymer or compatibilizer that contains functional groups to establish interactions with the blend phases $[14,15]$. The compatibilization process - where the additive is located at the interfaces of the components could improve the connection between the different polymer phases by creating new physical or chemical bonds $[16,17]$.

Because of the large number of additives more types can be appropriate for different materials, depending on whether the goal is to improve strength or the toughness. Therefore, it is important to investigate the effects of the additive on morphology and mechanical properties of blends because poorly selected compatibilizers could even impair the tensile properties of plastics without achieving morphological stability or the desired improvement in other physical and impact properties. The homogeneity of the phases can be improved with adequately selected compatibilizers based on the fact that additives can decrease domain sizes by inhibiting the coalescence phenomenon inside the polymer blend [18]. Recently, maleic anhydride (MA) has been one of the most industrially important reactive modifiers which promote compatibilization of immiscible polymer blends. MA, as a polyfunctional monomer, is widely used in the synthesis of reactive macromolecules to prepare high performance engineering and nano engineering polymers [19]. Grafting MA onto a polymer backbone provides high reactivity towards amines, alcohols, thiols and hydroxyl groups. Thereby, this reactive modifier is suitable for grafting onto polyolefins (e.g. HDPE-g-MA and PP-g-MA), ethylene-propylene-diene terpolymer (EPDM-g-MA) and hydrogenated styrene-butadiene-styrene terpolymer (SEBS-gMA) [20]. The effectiveness of PP-g-MA was previously demonstrated in blends of PS/PP [21], PP/PET [22], HDPE/PP [23] and PA12/PP [24]. Tóth et al. [25] reported positive effects of maleic-anhydride grafted polyolefins (PO-g-MA) on tensile and impact properties of $\mathrm{PE} / \mathrm{crumb}$ rubber system. HDPE-g-MA improved the mechanical properties of HDPE/chitosan composites in the research of Quiroz-Castillo et al [26]. The improved effect of SEBS-g-MA on impact properties has been proven in PET/HDPE blend in several studies [27-31]. It was also mentioned by Jogi et al. [32] and Hato et al. [33] that copolymers grafted with maleic anhydride promoted the compatibility between plastics and organoclays in nanocomposites. 
Compatibilizing blends also promotes polymer waste recycling because the additive can reduce the brittleness of the mixed plastic waste [34].

Polystyrene (PS) and high density polyethylene (HDPE) are among the most widely used lowcost plastics [35]. PS and HDPE are frequently used in packaging and everyday products; thereby they are often mixed together which implies that their mixed waste occurs too, although they are incompatible with each other. Because of economic and environmental reasons these wastes are recycled in increasing amounts [36,37]. In order to avoid the costs of the separation process, a large number of papers have been presented on PS/PE blends to study and to improve their common properties [38-43]. PS is a typically brittle polymer with high Young's modulus, while it can be characterised with low impact resistance and low elongation at break, which can be improved using polyethylene [44]. Therefore, blending PS and HDPE is an ideal combination to create a new material and achieve good physical or mechanical properties, where HDPE can be characterized with high impact resistance and flexibility, while PS has higher heat resistance and Young's modulus [35,45].

The mentioned PS and HDPE pair is a common example of compatibilization problems. Moreover, the necessary amount of compatibilizer is also difficult to ascertain when these plastics are mixed together [46]. Using block copolymers as additive compatiblizers or graft copolymers as reactive additives is a good way to enhance the properties of PS/PE blends further $[47,48]$. One way is to graft PE chains onto PS with in situ Friedel-Crafts alkylation reaction $[12,15,49,50]$ to obtain the suitable copolymer, PE-g-PS, or use block copolymer of polystyrene and polyethylene (PE-b-PS) [51,52]. Some research mentioned styrene-butadiene copolymer (SB) [53] and styrene/butadiene/styrene block copolymer (SBS) [52] as a potential additive for compatibilizing PS and PE with each other, in other papers the effectiveness of polyether copolymer (PEC) [54], hydrogenated butadiene-polystyrene copolymers (SEB) [55] and ethylene/styrene interpolymers [47] were also investigated. However, the most commonly used compatibilizer for improving the miscibility of PS and PE is styrene/ethylene/butylene/styrene block copolymer (SEBS) and its maleic anhydride grafted type (SEBS-g-MA), with which adhesion can be improved between the phases to prepare blends with better toughness [35,44,45,56-73].

Previously Sahnoune et al. [72] and Ha et al. [73] compared the effectiveness of SEBS and SEBS-g-MA in PS/HDPE blends, where both copolymers showed a good compatibilizing effect. Sahnoune et al. [72] found that PS and HDPE were immiscible with each other in a 75/25 HDPE/PS blend, where the fracture path spread in the boundary of PS and HDPE, due to the poor interfacial adhesion between the phases. When SEBS or SEBS-g-MA was added to the HDPE/PS blends, a significant reduction was detected in the size of dispersed PS. In addition, the fracture path passed through PS domains, what indicated that both SEBS and SEBS-g-MA promoted adhesion between the dispersed PS phases and the HDPE matrix. Investigation of mechanical properties revealed that a larger amount of compatibilizer did not make a significant change in yield strength, while Young's modulus slightly decreased. At the same time a large improvement in Charpy impact strength was achieved. Ha et al. [73] investigated a symmetrical 50/50 composition of PS/HDPE. They also mentioned that the blend showed gross phase separation, where the PS domain size was in a range of 8-30 $\mu \mathrm{m}$ in diameter. It was found that 
both compatibilizers were efficient; however, the domain sizes were smaller in blends containing SEBS, especially if the amount of additive was more than $10 \mathrm{vol} \%$. The results of differential scanning calorimeter (DSC) showed a slight change in the melting point of HDPE when SEBS or SEBS-g-MA was added to the blends, because increasing the amount of grafted copolymers in blends decreases relative crystallinity. Tensile tests showed that Young's modulus and tensile strength decreased when compatibilizers were added to the blend, while elongation at break of blends increased, regardless of whether SEBS or SEBS-g-MA was used. However, it can be mentioned when a smaller amount of additive (less than 10 vol\%) was used in PS/HDPE blends, better mechanical properties were achieved with using SEBS-g-MA.

Based on the study of literature, the examination of compatibilizer adequacy requires complex resources, which are expensive and time-consuming. During processing it is necessary to manufacture standard specimens for the further examination of mechanical and morphological properties, and the evaluation of experiment results takes a long time and requires great expertise. Therefore, a new evaluation method would be desirable to verify compatibilizers for the industrial field and for research in the area of polymer blends. The aim of the paper is to develop a novel method which provides a quick and clear answer regarding the adequacy of compatibilizers and determines how much additive needs to be added to polymer blends. The novel evaluation process is presented through a separation process driven by centrifugal force, in melted state of 50/50 vol\% PS/HDPE blends containing different amounts of SEBS-g-MA. The results and the effectiveness of the novel testing method are compared with the results of scanning electron microscopy, rheology measurements, tensile and impact tests.

\section{Experimental}

\subsection{Materials}

PS and HDPE were used to prepare blends in 50/50 vol\%, where PS was Edistir N 1840 (density $1.05 \mathrm{~g} / \mathrm{cm}^{3}$, melt flow rate $\left.10 \mathrm{~g} / 10 \mathrm{~min}\left(200^{\circ} \mathrm{C} / 5 \mathrm{~kg}\right)\right)$ provided by Versalis S.p.A and HDPE was Liten MB 87 (density $0.955 \mathrm{~g} / \mathrm{cm}^{3}$, melt flow rate $23 \mathrm{~g} / 10 \mathrm{~min}\left(190^{\circ} \mathrm{C} / 2.16 \mathrm{~kg}\right.$ )) produced by Unipetrol RPA. Kraton FG1901X, a type of SEBS-g-MA (density $0.908 \mathrm{~g} / \mathrm{cm}^{3}$, melt flow rate $22 \mathrm{~g} / 10 \mathrm{~min}\left(230^{\circ} \mathrm{C} / 5 \mathrm{~kg}\right), 1.4-2.0 \%$ maleic anhydride and $30 \%$ polystyrene content) produced by Kraton Polymers was added to the blends in 9 different content ratios ( 0 vol\%; 0.125 vol\%; 0.25 vol\%; 0.5 vol\%; 1 vol\%; 2 vol\%; 4 vol\%; 6 vol\%; 10 vol\%). DuPont Fusabond E100 (density $0.954 \mathrm{~g} / \mathrm{cm}^{3}$, melt flow rate $2 \mathrm{~g} / 10 \mathrm{~min}\left(190^{\circ} \mathrm{C} / 2.16 \mathrm{~kg}\right.$ ) a type of maleic anhydride grafted high density polyethylene (HDPE-g-MA) and Arkema OREVAC CA100 (density $0.905 \mathrm{~g} / \mathrm{cm}^{3}$, melt flow rate $10 \mathrm{~g} / 10 \mathrm{~min}\left(230^{\circ} \mathrm{C} / 0.225 \mathrm{~kg}\right)$ ) a type of maleic anhydride grafted polypropylene (PP-g-MA) were also used during the separation process in 4 vol\% to verify the adequacy of the developed novel method.

\subsection{Compoundation and sample preparation}

Extrusion was carried out in a Labtech Scientific LTE 26-44 twin screw extruder (temperature zones 230 to $255^{\circ} \mathrm{C}$, rotation speed $75 \mathrm{rpm}$ ). Granulation was realised after cooling in water 
bath, therefore the 50/50 PS/HDPE granules had to be dried in an air drying oven at $60^{\circ} \mathrm{C}$ for 2 hours in order to remove moisture adhered to the surface.

The samples were injection moulded in an Arburg Allrounder Advance 370S 700-290, where the following parameters were set: melt temperature $255 \pm 5^{\circ} \mathrm{C}$, mould temperature $40^{\circ} \mathrm{C}$, injection flow $30 \mathrm{~cm}^{3} / \mathrm{s}$, injection volume $46 \mathrm{~cm}^{3}$, holding pressure $300 \pm 50 \mathrm{bar}$ - depending on the mixtures, cycle time $50 \mathrm{~s}$ ).

\subsection{Characterization}

\subsubsection{Rheology}

The viscosities of the different SEBS-g-MA-containing blends were recorded using an AR2000 rheometer (TA Instruments) in plate-plate configuration. Two $25 \mathrm{~mm}$ diameter parallel discs were used to compression mould the blends for 5 minutes at $255^{\circ} \mathrm{C}$.

\subsubsection{Morphology}

JEOL JSM 6380LA scanning electron microscope (SEM) was used at an acceleration voltage of $15 \mathrm{kV}$ in secondary electron imaging mode to study the morphological structures of the blends after $45 \mathrm{~s}$ gold coating.

\subsubsection{Mechanical tests}

Tensile tests were performed on a Zwick Z020 Tester (test speed $20 \mathrm{~mm} / \mathrm{min}$, clamping distance $100 \mathrm{~mm}$ ) at room temperature, and were repeated 5 times for each composition. The cross section of the injection moulded specimens was $10 \times 4 \mathrm{~mm}$, according to standard ISO 527 .

Charpy impact tests were carried out in a Ceast Resil Impactor Junior impact test machine (15 $\mathrm{J}$ hammer, impact rate $3.4 \mathrm{~m} / \mathrm{s}$, distance between supports $62 \mathrm{~mm}$ ), and were repeated 6 times for each composition of the unnotched samples, the size of which were 80x10x4 mm (according to ISO 179-1).

\subsubsection{Novel separating method}

Fig. 1 shows the second generation, own constructed horizontal separator, in which the separation of the compatibilized blends occurs in melted state due to centrifugal force. The principles of the separation equipment have been described in our previous studies [74,75]. Briefly, the three separation tanks spin together with the shaft, which is rotated with an AC motor. Therefore, shear forces are small under steady state condition. The separation of blends is caused by three apparent forces: centrifugal force, Coriolis-force and Euler-force, where the latter can be negligible. Eq. (1) shows the force difference between the particle and medium, from where the higher density droplet migrates outward to the denser medium. The separation force depends on the density of the particle and the applied spinning speed, in 1D case at small Reynolds number $(R e<1)$, where the particle and the medium have different densities.

$$
\Delta F_{c f}=\left(\rho_{a}-\rho_{m}\right) \cdot V_{a} \cdot a_{c f}=\left(\rho_{a}-\rho_{m}\right) \cdot V_{a} \cdot r \cdot\left(2 \cdot \pi \cdot n_{c, m} / 60\right)^{2}
$$


where $\Delta F_{c f}$ is difference of the apparent centrifugal force between the particle and medium, which promotes the migration of the droplet because of density difference; $a_{c f}$ is the centripetal acceleration; $r$ is the distance between the axis of rotation and the particle; $\mathrm{n}_{\mathrm{c}, \mathrm{m}}$ is the rotational speed of the equipment in rpm; $\rho_{\mathrm{m}}$ is the density of the lower density medium, from where the droplet migrate; $\rho_{\mathrm{a}}$ and $V_{\mathrm{a}}$ are the density and the volume of particle $a$, respectively.

Owing to the influence of the centrifugal and Coriolis force, the higher density of the molten droplet can migrate towards the outer side of the melt, while phases with smaller density move towards the inner side, nearby the shaft during the spinning phase of the separation process. Since centripetal acceleration is significantly higher than the acceleration of gravity the influence of the latter can be neglected. The effectiveness of separation strongly depends on the applied melting temperature and the size of particles also has an effect.

The blends used in the separation process were compounded in the same way as in the other investigations. The total weight of each blend, with different SEBS-g-MA contents was $50 \mathrm{~g}$. The separator, in which the blends were also situated, was heated in a furnace, where heating time was 60 minutes for every sample at $300^{\circ} \mathrm{C}$ in order to achieve the fully melted state of blends. After heating 20 minutes of spinning at $2000 \mathrm{~min}^{-1}$ rotational speed followed at the same temperature. Finally, the shape of the samples was fixed inside the separator by air cooling, also during spinning.

\subsubsection{Verification of separation results by optical microscopy}

An Olympus BX 51M optical microscope was used (10x objective) to determine the effectiveness of disc separation at different compatibilizer contents. Stuers LaboPol-5 automatic polishing machine was used to prepare the samples to $5 \mu \mathrm{m}$ accuracy.

\subsubsection{Verification of separation purity by Fourier transform-infrared spectroscopy}

To verify the success of PS/HDPE blend separation without compatibilizer Fourier transforminfrared spectroscopy (FTIR) was utilised. To prepare the spectra of the samples an attenuated total reflection (ATR) setup placed in a Bruker Tensor 27 spectrometer was used with a spectral resolution of $1 \mathrm{~cm}^{-1}$ in the range from $600 \mathrm{~cm}^{-1}$ to $4000 \mathrm{~cm}^{-1}$.

\section{Results and discussion}

\subsection{Morphology}

Fig. 2 presents the morphology of the core of 50/50 PS/HDPE blends with different SEBS-gMA content from 0 vol\% to $10 \mathrm{vol} \%$, after injection moulding. As it can be seen, the compatibilizer has a significant effect on the morphology of injection moulded blends. If PS/HDPE blends without compatibilizer are compared with blends that conatin SEBS-g-MA, it can be stated the compatibilizer reduces the size of the dispersed phase. Blends without SEBSg-MA show a wider droplet size distribution, where droplet diameter is often greater than 10 $\mu \mathrm{m}$. On the other hand a more homogeneous structure formed when 10 vol\% SEBS-g-MA was 
added to the PS/HDPE blend. In this composition the average size of droplets decreased by more than half with a narrower range of droplet size. This phenomenon can be explained by the presence of SEBS-g-MA which reduced the interfacial tension between the PS and HDPE phases [66] due to formation of new bonds, and prevented coalescence leading to a more stable morphology with a smaller droplet size in the dispersed phase. When SEBS-g-MA is located at the interface between PS and HDPE, the styrene blocks of SEBS-g-MA is miscible with PS, while the hydrogenated ethylene-butadiene blocks could form entanglements with the HDPE phases. Previously the thermal behaviour of PS/HDPE blends was investigated, and it was found that the compatibilizer decreased the crystallinity of HDPE [44,62,73] due to the dilution with ethylene-butadiene segments of SEBS. Abis et al. [70] mentioned that binary PS/HDPE blends did not show any changes in their DSC parameters, addition of $10 \%$ compatibilizer resulted in a decrease of the crystallization and melting temperatures, which indicated the compatibilization effect. These statements may be supported by the fact that fracture path spread in the boundary of the phases up to 1 vol\% of SEBS-g-MA (Fig. 2/a-e), while from 2 vol\% of compatibilizer the fracture path passed through the PS domains (Fig 2/f-i), because of the reaction of the components. In our study the morphology developed at different SEBS-gMA contents show good agreement with the results of Sahnoune et al. [72].

\subsection{Rheology}

The viscosities of PS, HDPE and SEBS-g-MA are presented as a function of shear rates $(\dot{\gamma})$ in Fig. 3. In the range of the measured shear rate the viscosity of HDPE is nearly constant (319 $\mathrm{Pa} \cdot \mathrm{s}$ at $0.1 \mathrm{~s}^{-1}, 296 \mathrm{~Pa} \cdot \mathrm{s}$ at $\left.10 \mathrm{~s}^{-1}\right)$. The viscosity of PS slightly decreased from $933 \mathrm{~Pa} \cdot \mathrm{s}$ to 618 $\mathrm{Pa} \cdot \mathrm{s}$. The rheological property of SEBS-g-MA changed differently than PS and HDPE and showed greater shear thinning behaviour (especially around $1 \mathrm{~s}^{-1}$ shear rate). As it can be seen, PS can be characterized by minimum two time higher viscosity in the whole range than HDPE, assuming that HDPE forms easier the continuous structure in 50/50 vol\% PS/HDPE blend because of its higher flowability.

The influence of SEBS-g-MA on the viscosity of 50/50 PS/HDPE blends at $255^{\circ} \mathrm{C}$ is presented in Fig. 4, where blends show shear thinning behaviour in the investigated range of shear rate. Comparing the effects of the compatibilizer, it can be stated that blend without compatibilizer shows the smallest viscosity (495 Pa.s at $0.1 \mathrm{~s}^{-1}$ ) and the incorporation of SEBS-g-MA in the PS/HDPE blend causes an enhancement in viscosity, particularly at low shear rates. In addition, by increasing the amount of SEBS-g-MA in the blends further growth of viscosity can be achieved at the same shear rate, thus the highest viscosities $\left(2192 \mathrm{~Pa} \cdot \mathrm{s}\right.$ at $\left.0.1 \mathrm{~s}^{-1}\right)$ were measured at 10 vol\% SEBS-g-MA-containing PS/HDPE blends. The rheological results also show that SEBS-g-MA is able to make interaction with PS and HDPE phases, resulting in an increase in the viscosity of blends. Similar results were reported by Lin et al. [76] and Jafari et al. [77].

\subsection{Tensile tests}

Fig. 5 shows the stress-strain curves of 50/50 PS/HDPE with increasing SEBS-g-MA content in blends. In a range of 0-1 vol\% SEBS-g-MA the elongation at break of the blends was smaller than $3 \%$, and that reveals the brittleness of these blends. A change in the characteristics of the curves can be observed above 2 vol\% SEBS-g-MA, where the blends show a slight decrease in 
tensile strength, while a huge improvement can be detected in case of elongation at break. When 10 vol\% of SEBS-g-MA was added to the PS/HDPE blends, no fracture occurred before $20 \%$ elongation. As the amount of compatibilizer increases, the blends tend to become tougher.

If the results of tensile strength (Fig. 6/a) and Young's modulus (Fig. 6/b) tests of the blends are compared, the highest tensile strength $(25.98 \pm 0.19 \mathrm{MPa})$ and modulus $(1.54 \pm 0.04 \mathrm{GPa})$ values were measured in blends without compatibilizer. It can be observed that the recorded curves can be divided into two lines in both cases. The slope of the curves is steeper in absolute terms in the range of 0-1 vol\% SEBS-g-MA than between 2 and $10 \%$, and it means that the curves have a sharp breakpoint between 1 and 2 vol\% compatibilizer content. Tensile strength decreased by $5.5 \%(24.5 \mathrm{MPa})$, as the amount of compatibilizer increased to $2 \mathrm{vol} \%$. In case of the blend that contained $10 \%$ SEBS-g-MA a further decrease can be observed in tensile strength (22.9 MPa). This value is $12 \%$ lower than in case of blends without compatibilizer. This phenomenon can be supported by the fact that the finer morphological structure leads to a transition from brittle to ductile fracture [78], as it can be seen in Fig. 2. The ductility of polymer blends in most cases increases with finer phase distribution due to the smaller awakening stress when a smaller particle cracks $[35,61]$. A similar trend can be followed in case of the Young's modulus curve to what was described at tensile strength measurement, i.e. the increasing amount of compatibilizer resulted in a decrease in Young's modulus (1.5 GPa at 0 vol\%, 1.2 $\mathrm{GPa}$ at 10 vol\% of SEBS-g-MA). The presented tensile values are in good agreement with previous results $[44,61,63,72]$. The slight decrease in tensile strength and Young's modulus was expected because of the rubbery nature of SEBS-g-MA [73]. However, it should be mentioned that the elongation at break of PS/HDPE blends increased significantly, when SEBS-g-MA was added to blends.

\subsection{Charpy impact test}

As it can be seen in Fig. 7, a large improvement in the Charpy impact strength of PS/HDPE blend was realized by increasing the amount of compatibilizer. Blends with 10\% SEBS-g-MA content show a nearly eight times higher impact value $\left(73.1 \pm 11.4 \mathrm{~kJ} / \mathrm{m}^{2}\right)$ than blends without compatibilizer $\left(9.4 \pm 0.5 \mathrm{~kJ} / \mathrm{m}^{2}\right)$. Similarly to the results of tensile tests the curve can be characterized by a greater slope in the range of 2-10 vol\% SEBS-g-MA than at 0 to 1 vol\% SEBS-g-MA content. The slope of impact strength shows a breakpoint again between 1 and 2 vol\% of compatibilizer, as it was detected during the tensile test. Comparing the results of impact strength in pairs with independent two-sample t-test also shows that the first significant improvement was between 1 and 2 vol\% of SEBS-g-MA, from $11.5 \mathrm{~kJ} / \mathrm{m}^{2}$ to $14.0 \mathrm{~kJ} / \mathrm{m}^{2}$. A same improvement of impact strength of PS/HDPE blend with different SEBS-g-MA content was reported by Sahnoune et al [72].

\subsection{Investigation of compatibilizer adequacy in melted state}

During the novel separation process the compounded 50/50 vol\% PS/HDPE blends were the same as in other investigations, produced with a twin screw extruder. The adequacy of compatibilizers have been investigated in blends with different SEBS-g-MA content (0-10 vol\%). The separation occurred in melted state, utilising centrifugal force. Owing to the influence of centrifugal force, the melted PS droplets, which can be characterized with higher 
density than HDPE, can migrate towards the wall of the separation tank, while HDPE phases move towards the shaft during the spinning phase of the separation process. The separation process can result in three different types of zones as parts of the separated disc: a pure outer zone of PS, a pure inner zone of HDPE and a potential transition zone, wherein the two plastics and compatibilizer SEBS-g-MA can also be found at the same time. The thickness of the formed zones can be measured by optical microscopy, after the discs are polished. In case the PS/HDPE blend did not contain compatibilizer, the melted phases solidified during shape-fixing and formed two separated, pure zones in the disc with a sharp transition boundary, i.e. the outer zone contained only PS and only HDPE was located in the inner zone (Fig. 8/a). Conversely, when $0.5 \%$ SEBS-g-MA was added to PS/HDPE blend a large transient, compatibilized zone formed between the neat HDPE and neat PS zone (Fig 8/c).

The result of the separation process was supported by FTIR measurements. The FTIR spectra from the outer and inner zones of the samples were compared with the FTIR spectra of the reference PS and HDPE, in order to verify the purity of the separated zones (Fig. 8/b). The samples were taken from the two different zones of the separated 50/50 PS/HDPE disc without SEBS-g-MA. The sampling from 50/50 PS/HDPE disc with $0.5 \%$ SEBS-g-MA occurred from the outer, the transition and the inner zone too (Fig. 8/d). HDPE can be characterized with three sets of peaks as a result of C-H and C-C absorption. Peak set in a range of $2800-3000 \mathrm{~cm}^{-1}$ correspond to $\mathrm{C}-\mathrm{H}$ stretch bond, where the higher wave number $\left(2917 \mathrm{~cm}^{-1}\right)$ is the asymmetric stretch bond of $\mathrm{CH}_{2}$, while the lower peak $\left(2848 \mathrm{~cm}^{-1}\right)$ belongs to the symmetric stretch bond of $\mathrm{CH}_{2}$. A strong bending was detected in the range of $1460-1470 \mathrm{~cm}^{-1}$ which corresponds to $\mathrm{CH}_{2}$ groups, too. The peak centred at $719 \mathrm{~cm}^{-1}$ is the rocking of the methylene group of HDPE. The differences of peaks in PS can be explained by the presence of the aromatic ring. The aromatic C-H stretching vibration of PS is clearly visible in the range from 3083 to $3025 \mathrm{~cm}^{-1}$. Peaks at $2922 \mathrm{~cm}^{-1}$ and $2853 \mathrm{~cm}^{-1}$ correspond to aliphatic $\mathrm{C}-\mathrm{H}$ stretching of the backbone chain. The peak of $1601 \mathrm{~cm}^{-1}$ is strong and independent, corresponding to the aromatic $\mathrm{C}-\mathrm{C}$ stretching bond, while peaks of $1493 \mathrm{~cm}^{-1}$ and $1451 \mathrm{~cm}^{-1}$ correspond to both the aromatic and the backbone chain. The out-of-plane C-H bends of the aromatic ring of PS are intense in the range of 753$694 \mathrm{~cm}^{-1}$. If the spectra of the reference materials and the samples of different zones from the separated 50/50 PS/HDPE disc without SEBS-g-MA are compared, it can be stated undoubtedly, that the outer zone is pure PS and the inner zone consists of HDPE without detectable contamination. In the other case, the characteristic peaks of PS and HDPE also can be found in spectra of the sample from transition zone of disc with $0.5 \%$ SEBS-g-MA. The obtained results from FTIR test show full agreement with the spectroscopic studies (Fig. 9).

The evaluation of the discs after separation revealed, that if blends did not contain compatibilizer or the presence of SEBS-g-MA was low, the separation of PS and HDPE was successful. However, increasing the amount of SEBS-g-MA from 0 vol $\%$ to 0.5 vol $\%$ resulted in continuous increase in the thickness of transition compatibilized zone. This phenomenon can be explained by the compatibilizing effects of SEBS-g-MA between the phases of PS and HDPE (Fig. 9). If 0.125 vol\% SEBS-g-MA was added to blends the thickness of transition zone increases to $2746 \mu \mathrm{m}$ from the initial thickness of $282 \mu \mathrm{m}$, measured at 0 vol\% of SEBS-g-MA. If the presence of the compatibilizer was $0.25 \mathrm{vol} \%$ in PS/HDPE blend the thickness of 
homogeneous PS and HDPE phases decreased further, particularly in case of PS; whereas the transition compatibilized zone was the thickest $(6096 \mu \mathrm{m})$, almost as thick as the total thickness of two homogeneous PS $(1711 \mu \mathrm{m})$ and HDPE $(4794 \mu \mathrm{m})$ zones, as it can be seen on the surface of the disc. At 0.5 vol\% SEBS-g-MA the thickness of the PS zone is close to $1 \mathrm{~mm}$. When the amount of the compatibilizer was increased further up to 1 vol\% the homogeneous PS zone disappeared, only a thin $(857 \mu \mathrm{m})$ HDPE zone formed besides a thick heterogeneous, compatibilized zone. Finally, only a compatibilized zone formed in the total cross-section of the disc at 2 vol\% SEBS-g-MA, and that has become more homogeneous as the amount of SEBS-g-MA increased.

As the optical microscope images of the discs are summarized in one diagram, the change in the ratio of phase thickness as a function of SEBS-g-MA content is shown in Fig. 10. Based on the separation experiments it can be stated that from 2 vol\% of SEBS-g-MA is an effective compatibilizer in PS/HDPE blends, as in the range of 2 to 10 vol\% SEBS-g-MA content it was not possible to separate the two phases from each other. This is presumably due to the fact that introducing SEBS-g-MA to PS/HDPE blend leads to a finer particle size distribution up to $2 \%$ SEBS-g-MA (Fig. 2). Above 4\% compatibilizer, the average diameter of the dispersed phase was nearly the same (Fig. 2/g-i). When PS/HDPE blend did not contain SEBS-g-MA a coarsened morphology developed and the separation occurred at high purity. Adding small amount of SEBS-g-MA to PS/HDPE blend resulted in smaller droplets, on which lower centrifugal force acts. Because of the lower centrifugal force and the entanglements between the phases only a partial separation occurred between $0.125 \%$ and $1 \%$ SEBS-g-MA content. From $2 \%$ compatibilizer content the polymer blend system started homogeneous due to higher concentration of SEBS-g-MA, and the size of droplets reached a critical value, where the separation did not take place between the phases because of the small awakening forces and the entanglements between the phases.

If the results of the separation process are compared with the results of tensile tests and Charpy impact tests a high degree of similarity can be detected. The characteristics of stress-strain curves were also changed between 1-2\% SEBS-g-MA content, while the Charpy impact strength was starting to significantly increase from $2 \%$ compatibilizer. In case of 1 vol\% SEBSg-MA only a compatibilized zone can be found in the outer zone instead of pure PS but pure HDPE could be recovered in small amount. When SEBS-g-MA content was raised up to 2 vol\% the pure HDPE zone vanished and in total cross-section of the disc only a heterogeneous, compatibilized zone formed, what means that PS and HDPE plastics have not been able to be recovered above 2 vol\% SEBS-g-MA after separation. These results indicate the compatibilizing effect of SEBS-g-MA from $2 \%$ content. Of course it should be noted, if the main target is to achieve a tougher blend, further amount of compatibilizer is necessary to add to PS/HDPE blend.

\subsection{Verification of the novel evaluation method in melted state}

Two other compatibilizers, HDPE-g-MA and PP-g-MA were also investigated in order to verify the adequacy of SEBS-g-MA with the novel separation method. Taking into account the results of investigation of SEBS-g-MA (where the compatibilization was successful above 2 vol\% 
content), the amount of additive was doubled: in one case 4 vol\% of HDPE-g-MA, in the other case 4 vol\% of PP-g-MA was added to PS/HDPE blends in the stage of compoundation in a twin-screw extruder, using the same processing parameters. The separation results of these blends with higher HDPE-g-MA or PP-g-MA content show that separation occurred between the phases of PS and HDPE (Fig. 11). In both cases a sharp transition boundary can be seen and it can be assumed that the additives can be found in the zone of HDPE. However, it should be mentioned that detecting parts of HDPE-g-MA is more difficult (Fig. 11/a), than detecting PPg-MA (Fig. 11/b) in HDPE. Since the additives of HDPE-g-MA and PP-g-MA do not contain blocks or groups which can establish interaction with PS, the separation successfully occurred in these two cases, as in the case of 50/50 PS/HDPE blends without compatibilizer (Fig. 9).

\section{Conclusion}

In this study a novel separation method was developed in order to determine the minimum required amount of SEBS-g-MA to achieve good compatibilization between PS and HDPE phases, compared with the results of the most commonly used evaluation methods. The results show that SEBS-g-MA has a significant effect on the rheology, morphology and mechanical properties, furthermore also on the separability of 50/50 PS/HDPE blends. During the rheology experiment a consistent increase in viscosity was detected in the inspected range of shear rates, when compatibilizer was added to blends. If the amount of SEBS-g-MA increased, a finer morphology has developed, and at 1 vol\% compatibilizer content the average droplet size decreased compared to the size distribution of the PS/HDPE blend without SEBS-g-MA; although in many cases the droplet sizes were larger than 5 to $10 \mu \mathrm{m}$ in diameter, the adhesion with the matrix was weak. As a result of adding 2 vol\% SEBS-g-MA to the blend the loose boundaries between the phases disappeared with a further droplet size decrease.

After the evaluation of mechanical test results a sharp breakpoint was observed in the curves of tensile strength and Young's modulus between 1 and 2 vol\% SEBS-g-MA content. Similarly, a breakpoint was observed in the curve of Charpy impact strength, where a significant improvement occurred above 2 vol\% compatibilizer and the curve of impact strength became steeper. The most commonly used mechanical tests collectively showed that above 2 vol\% SEBS-g-MA the compatibilizer begins to cause measurable changes in the behaviour of blends, extending its influence on the morphology and mechanical properties of PS/HDPE blends.

The results of the novel separation process show that the PS and HDPE phases of blends, which were previously compounded in twin-screw extruder, could be at least partially separate from each other, when blends contained 0 to 1 vol\% SEBS-g-MA. From 2 to 10 vol\% compatibilizer content, SEBS-g-MA prevents the separation of PS and HDPE phases because of the lower centrifugal force due to the smaller droplet size distribution and entanglements between the phases. It has been proven that the results of the novel evaluation method based on separation are in good agreement with the results of the mechanical tests. The investigations show that SEBS-g-MA is an effective compatibilizer when at least 2 vol\% is added to the PS/HDPE blend. Other additives (HDPE-g-MA and PP-g-MA), which did not contain suitable groups to make interactions and bonds between PS and HDPE, were also investigated in order to verify the adequacy of the novel separation method. In these cases the separation was achieved by a sharp 
boundary among the pure PS and pure HDPE phases, similarly to the case when the blend did not contain compatibilizer. The results lead to the conclusion that the novel separation method, where the blends are investigated in melted state, and that uses centrifugal force can be suitable for predicting the adequacy of compatibilizer in polymer blends.

\section{References}

[1] Fekete E, Földes E, Pukánszky B (2005) Effect of molecular interactions on the miscibility and structure of polymer blends. Eur Polym 41:727-736. doi:10.1016/j.eurpolymj.2004.10.038

[2] Utracki LA, Mukhopadhyay P, Gupta RK (2014) Polymer blends: Introduction. In: Utracki LA, Wilkie CA (eds) Polymer blends handbook Vol 1, 2nd edn, Springer, Dordrecht, pp 3-170

[3] Van Eerdenbrugh B, Taylor LS (2012) Molecular weight effects on the miscibility behavior of dextran and maltodextrin with poly(vinylpyrrolidone). Pharm Res 29:2754-2765. doi:10.1007/s11095-012-0689-5

[4] Anastasiadis SH, Gancarz I, Koberstein JT (1988) Interfacial tension of immiscible polymer blends: Temperature and molecular weight dependence. Macromolecules 21:2980-2987. doi:10.1021/ma00188a015

[5] Wang D, Li Y, Xie X-M, Guo B-H (2011) Compatibilization and morphology development of immiscible ternary polymer blends. Polymer 52:191-200. doi:10.1016/j.polymer.2010.11.019

[6] Sperling LH (2005) Introduction to physical polymer science, 4th edn. Wiley, New York

[7] Imre B, Renner K, Pukánszky B (2014) Interactions, structure and properties in poly(lactic acid)/thermoplastic polymer blends. Express Polym Lett 8:2-14. doi:10.3144/expresspolymlett.2014.2

[8] Taylor GI (1932) The viscosity of a fluid containing small drops of another fluid. Proc R Soc Lond A 138:41-48. doi:10.1098/rspa.1932.0169

[9] Taylor GI (1934) The formation of emulsions in definable fields of flow. Proc R Soc Lond A 146:501-523. doi:10.1098/rspa.1934.0169

[10] Garstecki P, Fuerstman MJ, Stone HA, Whitesides GM (2006) Formation of droplets and bubbles in a microfluidic T-junction-scaling and mechanism of break-up. Lab Chip 6:437-446. doi:10.1039/B510841A

[11] Ramic AJ, Hudson SD, Jamieson AM, Manas-Zloczower I (2000) Temporary dropletsize hysteresis in immiscible polymer blends. Polymer 41:62623-6270. doi:10.1016/S0032-3861(99)00845-9

[12] Díaz MF, Barbosa SE, Capiati NJ (2007) Reactive compatibilization of PE/PS blends. Effect of copolymer chain length on interfacial adhesion and mechanical behavior. Polymer 48:1058-1065. doi:10.1016/j.polymer.2006.12.040

[13] Chandrasekharakurup SC, Shanks RA, Thomas S (2014) Polymer blends. In: Thomas S, Shanks RA, Chandrasekharakurup SC (eds) Nanostructured polymer blends Vol 1. William Andrew, Waltham, pp 1-14 
[14] Li Y-Y, Hu S-w, Sheng J (2007) Evolution of phase dimensions and interfacial morphology of polypropylene/polystyrene compatibilized blends during mixing. Eur Polym J 43:561-572. doi:10.1016/j.eurpolymj.2006.10.018

[15] Shahbazi Kh, Razavi Aghjeh MK, Abbasi F, Partovi Meran M, Mehrabi Mazidi M (2012) Rheology, morphology and tensile properties of reactive compatibilized polyethylene/polystyrene blends via Friedel-Crafts alkylation reaction. Polym Bull 69:241-259. doi:10.1007/s00289-012-0751-9

[16] Li Z, Liu CM, Liu HL, Wang K, Fu Q (2014) Non-uniform dispersion of toughening agents and its influence on the mechanical properties of polypropylene. Express Polym Lett 8:232-242. doi:10.3144/expresspolymlett.2014.27

[17] Marosi Gy (2011) Interfaces in Multiphase Polymer Systems. In: Boudenne L, Ibos L, Candau Y, Thomas S. (eds) Handbook of Multiphase Polymer Systems. Wiley, Chichester, pp 81-112

[18] Argoud A, Trouillet-Fonti L, Ceccia S, Sotta P (2014) Morphologies in polyamide 6/high density polyethylene blends with high amounts of reactive compatibilizer. Eur Polym J 50:177-189. doi:10.1016/j.eurpolymj.2013.10.026

[19] Rzayev ZMO (2011) Graft copolymers of maleic anhydride and its isostructural analogues: High performance engineering materials. Int Rev Chem Eng 3:153-215.

[20] Al-Malaika S (1997) Reactive modifiers for polymers, 1th edn. Chapman \& Hall, London

[21] Parameswaranpillai J, Joseph G, Chellappan RV, Zahakariah AK, Hameed N (2015) The effect of polypropylene-graft-maleic anhydride on the morphology and dynamic mechanical properties of polypropylene/polystyrene blends. J Polym Res 22:2. doi: 10.1007/s10965-014-0641-y

[22] Zhu Y, Liang C, Bo Y, Xu s (2015) Compatibilization of polypropylene/recycled polyethylene terephthalate blends with maleic anhydride grafted polypropylene in the presence of diallyl phthalate. J Polym Res 22:35. doi: 10.1007/s10965-014-0591-4

[23] Mariam Atiqah AAS, Salmah H, Firuz Z, Lan DNU (2014) Properties of recycled high density polyethylene/recycled polypropylene blends: Effect of maleic anhydride polypropylene. Key Eng Mat 594-595:837-841. doi: 10.4028/www.scientific.net/KEM.594-595.837

[24] Jose S, Thomas S, Parameswaranpillai J, Aprem AS, Karger-Kocsis J (2015) Dynamic mechanical properties of immiscible polymer systems with and without compatibilizer. Polym Test 44:168-176. doi: 10.1016/j.polymertesting.2015.04.008

[25] Tóth B, Varga Cs, Bartha L (2015) Olefin-maleic-anhydride copolymer based additives: A novel approach for compatibilizing blends of waste polyethylene and crumb rubber. Waste Manage 38:65-71. doi: 10.1016/j.wasman.2015.01.004

[26] Quiroz-Castillo JM, Rodríguez-Félix DE, Grijalva-Monteverde H, del Castillo-Castro T, Plascencia-Jatomea M, Rodríguez-Félix F, Herrera-Franco PJ (2014) Preparation of extruded polyethylene/chitosan blends compatibilizedwith polyethylene-graft-maleic anhydride. Carbohyd Polym 101:1094-1100. doi: 10.1016/j.carbpol.2013.10.052

[27] Lei Y, Wu Q, Zhang Q (2009) Morphology and properties of microfibrillar composites based on recycled poly (ethylene terephthalate) and high density 
polyethylene. Compos Part A-Appl S 40:904-912. doi:

10.1016/j.compositesa.2009.04.017

[28] Pluta M, Bartczak Z, Pawlak A, Galeski A, Pracella M (2001) Phase structure and viscoelastic properties of compatibilized blends of PET and HDPE recyclates. J Appl Polym Sci 82:1423-1436. doi: 10.1002/app.1980

[29] Kalfoglou NK, Skafidas DS, Kallitsis JK, Lambert J-C, Van der Stappen L (1995) Comparison of compatibilizer effectiveness for PET/HDPE blends. Polymer 36:44534462. doi: 10.1016/0032-3861(95)96853-Z

[30] Pracella M, Pazzagli F, Galeski A (2002) Reactive compatibilization and properties of recycled poly(ethylene terephthalate)/polyethylene blends. Polym Bull 48:67-74. doi: $10.1007 / \mathrm{s} 00289-002-0001-7$

[31] Dobrovszky K, Ronkay F (2015) Effects of SEBS-g-MA on rheology, morphology and mechanical properties of PET/HDPE blends. Int Polym Proc 30:91-99. doi: $10.3139 / 217.297$

[32] Jogi BF, Bhattacharyya AR, Poyekar A, Pötschke P, Simon GP, Kumar S (2015) The simultaneous addition of styrene maleic anhydride copolymer and multiwall carbon nanotubes during melt-mixing on the morphology of binary blends of polyamide6 and acrylonitrile butadiene styrene copolymer. Polym Eng Sci 55:457-465. doi: 10.1002/pen.23905

[33] Hato MJ, Motaung TE, Choi HJ, Scriba M, Khumalo VM, Malweal T (2015) Effect of organoclay on the properties of maleic-anhydride grafted polypropylene and poly(methyl methacrylate) blend. Polym Composite, in press. doi: 10.1002/pc.23601

[34] Gianoglio Pantano IA, Asteasuain M, Sarmoria C, Brandolin A (2012) Graft copolymers for blend compatibilization: Mathematical modeling of the grafting process. Macromol React Eng 6:406-418. doi:10.1002/mren.201200025

[35] Rek V, Vranješ N, Šlouf M, Fortelný I, Jelčić Z (2008) Morphology and properties of SEBS block copolymer compatibilized PS/HDPE blends. J Elastom Plast 40:237-251. doi:10.1177/0095244307084906

[36] Hamad K, Kaseem M, Deri F (2013) Recycling of waste from polymer materials: An overview of the recent works. Polym Degrad Stabil 98:2801-2812.

doi:10.1016/j.polymdegradstab.2013.09.025

[37] Elmaghor F, Zhang L, Li H (2003) Recycling of high density polyethylene/poly(vinyl chloride)/polystyrene ternary mixture with the aid of high energy radiation and compatibilizers. J Appl Polym Sci 88:2756-2762. doi:10.1002/app.11985

[38] Thirtha V, Lehman R, Nosker T (2006) Morphological effects on glass transition behavior in selected immiscible blends of amorphous and semicrystalline polymers. Polymer 47:5392-5401. doi:10.1016/j.polymer.2006.05.014

[39] Lazo NDB, Scott CE (1999) Morphology development during phase inversion of a PS/PE blend in isothermal, steady shear flow. Polymer 40:5469-5478. doi:10.1016/S0032-3861(98)00792-7

[40] Willemse RC, Speijer A, Langeraar AE, Posthuma de Boer A (1999) Tensile moduli of co-continuous polymer blends. Polymer 40:6645-6650. doi:10.1016/S00323861(98)00874-X 
[41] Willemse RC, Posthuma de Boer A, van Dam J, Gotsis AD (1998) Co-continuous morphologies in polymer blends: a new model. Polymer 39:5879-5887. doi:10.1016/S0032-3861(97)10200-2

[42] Min K, White JL, Fellers JF (1984) High density polyethylene/polystyrene blends: Phase distribution morphology, rheological measurements, extrusion, and melt spinning behavior. J Appl Polym Sci 29:2117-2142. doi:10.1002/app.1984.070290619

[43] Mekhilef N, Carreau PJ, Favis BD, Martin P, Ouhlal A (2000) Viscoelastic properties and interfacial tension of polystyrene-polyethylene blends. J Polym Sci Pol Phys 38:1359-1368. doi:10.1002/(SICI)1099-0488(20000515)38:10<1359::AIDPOLB130>3.0.CO;2-D

[44] Xu S-A, Chan C-M (1998) Polystyrene/high density polyethylene blends compatibilized by a tri-block copolymer I. Properties and morphology. Polym J 30:552-558. doi:10.1295/polymj.30.552

[45] Chen B, Li X, Xu S, Tang T, Zhou B, Huang B (2002) Compatibilization effects of block copolymers in high density polyethylene/syndiotactic polystyrene blends. Polymer 43:953-961. doi:10.1016/S0032-3861(01)00660-7

[46] Liu C-Y (2007) A novel method to characterize the compatibilizer effect in polymer blend. J Polym Sci Pol Phys 45:3215-3219. doi:10.1002/polb.21310

[47] Tang J, Tang W, Yuan H, Jin R (2007) Mechanical behaviors of ethylene/styrene interpolymer compatibilized polystyrene/polyethylene blends. J Appl Polym Sci 104:4001-4007. doi:10.1002/app.26031

[48] Pötschke P, Paul DR (2003) Formation of co-continuous structures in melt-mixed immiscible polymer blends. J Macromol Sci-Pol R 43:87-141. doi:10.1081/MC120018022

[49] Teh JW, Rudin A (1992) Compatibilization of a polystyrene-polyethylene blend through reactive processing in a twin screw extruder. Polym Eng Sci 32:1678-1686. doi:10.1002/pen.760322205.

[50] Gianoglio Pantano IA, Brandolin A, Sarmoria C (2011) Mathematical modeling of the graft reaction between polystyrene and polyethylene. Polym Degrad Stabil 96:416425. doi:10.1016/j.polymdegradstab.2011.01.016

[51] Galloway JA, Jeon HK, Bell JR, Macosko CW (2005) Block copolymer compatibilization of cocontinuous polymer blends. Polymer 46:183-191. doi:10.1016/j.polymer.2004.10.061

[52] Wang Z, Chan C-M, Zhu SH, Shen J (1998) Compatibilization of polystyrene and low density polyethylene blends by a two-step crosslinking process. Polymer 39:68016806. doi:10.1016/S0032-3861(98)00174-8

[53] Fortelný I, Mikešová J, Hromádková J, Hašová V, Horák Z (2003) Effect of molecular structure of styrene-butadiene block copolymers on morphology, rheological properties, and impact strength of polystyrene/polyethylene blends. J Appl Polym Sci 90:2303-2309. doi:10.1002/app.12730

[54] Schwarz MC, Barlow JW, Paul DR (1998) Mechanical properties of HDPE/(PEC/PS)/SEBS blends. J Appl Polym Sci 35:2053-2067. doi:10.1002/app.1988.070350806 
[55] Taha M, Frerejean V (1996) Morphology development of LDPE-PS blend compatibilization. J Appl Polym Sci 61:969-979. doi:10.1002/(SICI)10974628(19960808)61:6<969::AID-APP11>3.0.CO;2-Q

[56] Jelčić Z, Vranješ N, Rek V (2010) Long-range processing correlation and morphological fractality of compatibilized blends of PS/ HDPE/ SEBS block copolymer. Macromol Symp 290:1-14. doi:10.1002/masy.201050401

[57] Li J, Favis BD (2001) Characterizing co-continuous high density polyethylene/polystyrene blends. Polymer 42:5047-5053. doi:10.1016/S00323861(00)00785-0

[58] Veenstra H, Van Dam J, Posthuma de Boer A (2000) On the coarsening of cocontinuous morphologies in polymer blends: effect of interfacial tension, viscosity and physical cross-links. Polymer 41:3037-3045. doi:10.1016/S0032-3861(99)00455-3

[59] Kunyawut C (2006) A study of droplet coalescence in immiscible PS/LDPE blends under annealing conditions. Thammasat Int J Sc Tech 11(2):21-33.

[60] Iza M, Bousmina M, Jérôme R (2001) Rheology of compatibilized immiscible viscoelastic polymer blends. Rheol Acta 40:10-22. doi:10.1007/s003970000112

[61] Tjong SC, Xu SA (1998) Impact and tensile properties of SEBS copolymer compatibilized PS/HDPE blends. J Appl Polym Sci 68:1099-1108. doi:10.1002/(SICI)1097-4628(19980516)68:7<1099::AID-APP7>3.0.CO;2-A

[62] Bartczak Z, Galeski A, Pluta M (2000) Ternary blends of high-density polyethylenepolystyrene-poly(ethylene/butylene-b-styrene) copolymers: Properties and orientation behavior in plane-strain compression. J Appl Polym Sci 76:1746-1761. doi:10.1002/(SICI)1097-4628(20000620)76:12<1746::AID-APP4>3.0.CO;2-O

[63] Xu SA, Tjong SC (2000) Deformation mechanisms and fracture toughness of polystyrene/high-density polyethylene blends compatibilized by triblock copolymer. J Appl Polym Sci 77:2024-2033. doi:10.1002/1097-4628(20000829)77:9<2024::AIDAPP19>3.0.CO;2-3

[64] Chirawithayaboon A, Kiatkamjornwong S (2004) Compatibilization of high-impact polystyrene/high-density polyethylene blends by styrene/ethylene-butylene/styrene block copolymer. J Appl Polym Sci 91:742-755. doi:10.1002/app.13215

[65] Nam GJ, Kim KY, Lee JW (2005) The effect of SEBS on interfacial tension and rheological properties of LDPE/PS blend. J Appl Polym Sci 96:905-911. doi:10.1002/app.21536

[66] Mekhilef N, Favis BD, Carreau PJ (1997) Morphological stability, interfacial tension, and dual-phase continuity in polystyrene-polyethylene blends. J Polym Sci Pol Phys 35:293-308. doi:10.1002/(SICI)1099-0488(19970130)35:2<293::AIDPOLB7>3.0.CO;2-T

[67] Bourry D, Favis BD (1998) Cocontinuity and phase inversion in HDPE/PS blends: Influence of interfacial modification and elasticity. J Polym Sci Pol Phys 36:18891899. doi:10.1002/(SICI)1099-0488(199808)36:11<1889::AID-POLB10>3.0.CO;2-3

[68] Harrats C, Fayt R, Jérôme R, Blacher S (2003) Stabilization of a cocontinuous phase morphology by a tapered diblock or triblock copolymer in polystyrene-rich lowdensity polyethylene/polystyrene blends. J Polym Sci Pol Phys 41:202-216. doi:10.1002/polb.10370 
[69] Li J, Ma PL, Favis BD (2002) The role of the blend interface type on morphology in cocontinuous polymer blends. Macromolecules 35:2005-2016.

doi:10.1021/ma010104+

[70] Abis L, Abbondanza L, Braglia R, Castellani L, Giannotta G, Po R (2000)

Syndiotactic polystyrene/high-density polyethylene blends compatibilized with SEBS copolymer: thermal, morphological, tensile, dynamic-mechanical, and ultrasonic characterization. Macromol Chem Physic 201:1732-1741. doi:10.1002/15213935(20000901)201:14<1732::AID-MACP1732>3.0.CO;2-J

[71] Bureau MN, El Kadi H, Denault J, Dickson JI (1997) Injection and compression molding of polystyrene/high-density polyethylene blends-phase morphology and tensile behavior. Polym Eng Sci 37:377-390. doi:10.1002/pen.11680

[72] Sahnoune F, Lopez Cuesta JM, Crespy A (2003) Improvement of the mechanical properties of an HDPE/PS blend by compatibilization and incorporation of $\mathrm{CaCO}_{3}$. Polym Eng Sci 43:647-660. doi:10.1002/pen.10053

[73] Ha C-S, Park H-D, Kim Y, Kwon S-K, Cho W-J (1996) Compatibilizer in polymer blends for the recycling of plastics waste I: Preliminary studies on 50/50 wt $\%$ virgin polyblends. Polym Advan Technol 7:483-492. doi: 10.1002/(SICI)10991581(199605)7:5/6<483::AID-PAT511>3.0.CO;2-V

[74] Dobrovszky K, Ronkay F (2014) Alternative polymer separation technology by centrifugal force in a melted state. Waste Manage 34:2104-2112. doi:10.1016/j.wasman.2014.05.006

[75] Dobrovszky K, Csergő V, Ronkay F (2015) Alternative, new method for predicting polymer waste stream contents. Mater Sci Forum 812:247-252. doi:10.4028/www.scientific.net/MSF.812.247

[76] Lin X, Qian Q, Xiao L, Chen Q, Huang Q, Zhang H (2014) Influence of reactive compatibilizer on the morphology, rheological, and mechanical properties of recycled poly(ethylene terephthalate)/polyamide 6 blends. J Macromol Sci B 53:1543-1552. doi: 10.1080/00222348.2014.946840

[77] Jafari SH, Yavari A, Asadinezhad A, Khonakdar HA, Böhme F (2005) Correlation of morphology and rheological response of interfacially modified PTT/m-LLDPE blends with varying extent of modification. Polymer 46:5082-5093. doi:10.1016/j.polymer.2005.04.045

[78] Quintens D, Groeninckx G, Guest M, Aerts L (1990) Mechanical behavior related to the phase morphology of PC/SAN polymer blends. Polym Eng Sci 30:1474-1483. doi: 10.1002/pen.760302208 


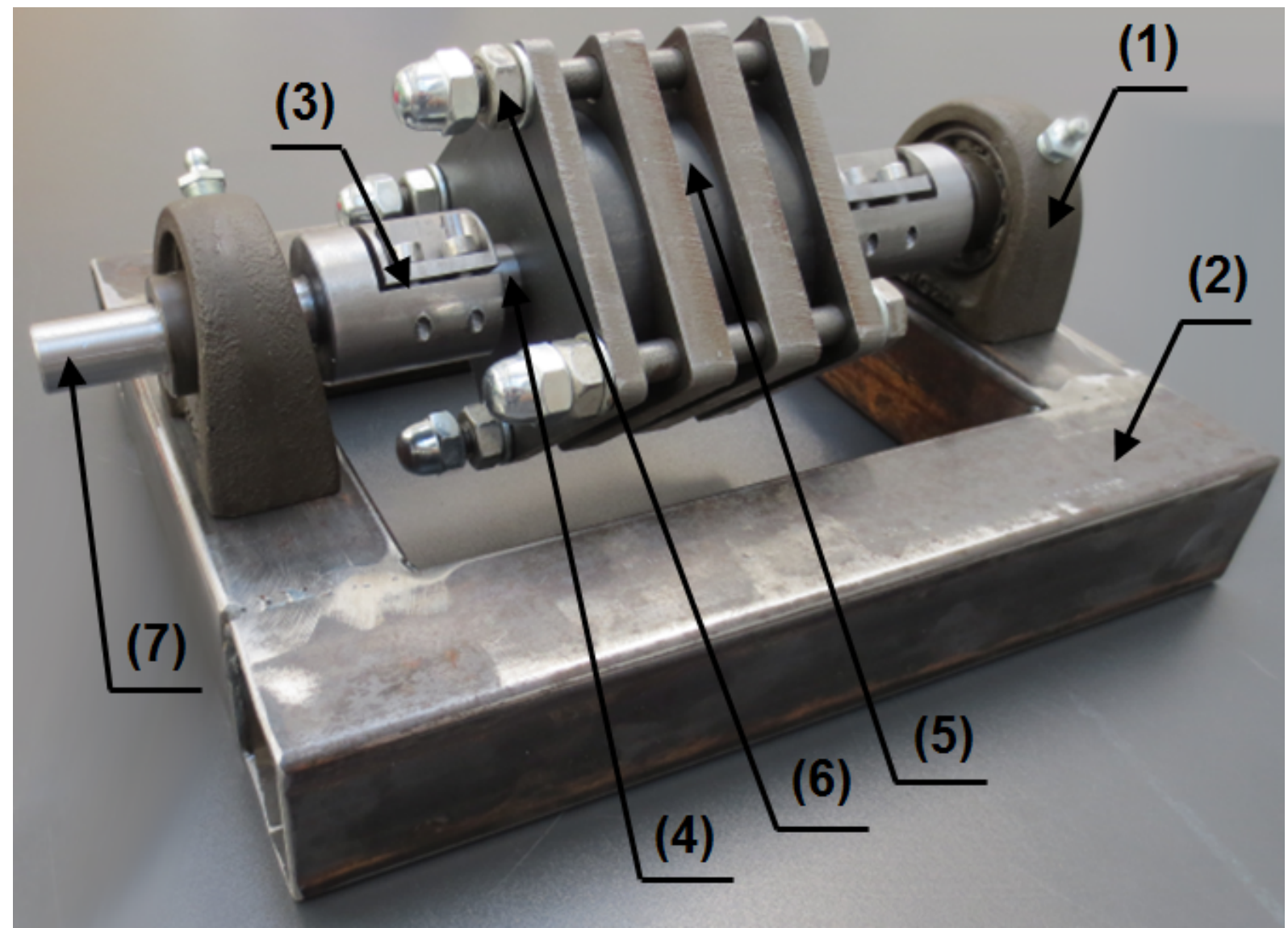

Fig. 1. The own constructed horizontal separator: (1) bearing housing; (2) welded frame; (3) soluble coupling; (4) shaft of $18 \mathrm{~mm}$ diameter; (5) three separation tanks of 82,5 mm outer diameter; (6) clamping anchors; (7) connection to AC motor 

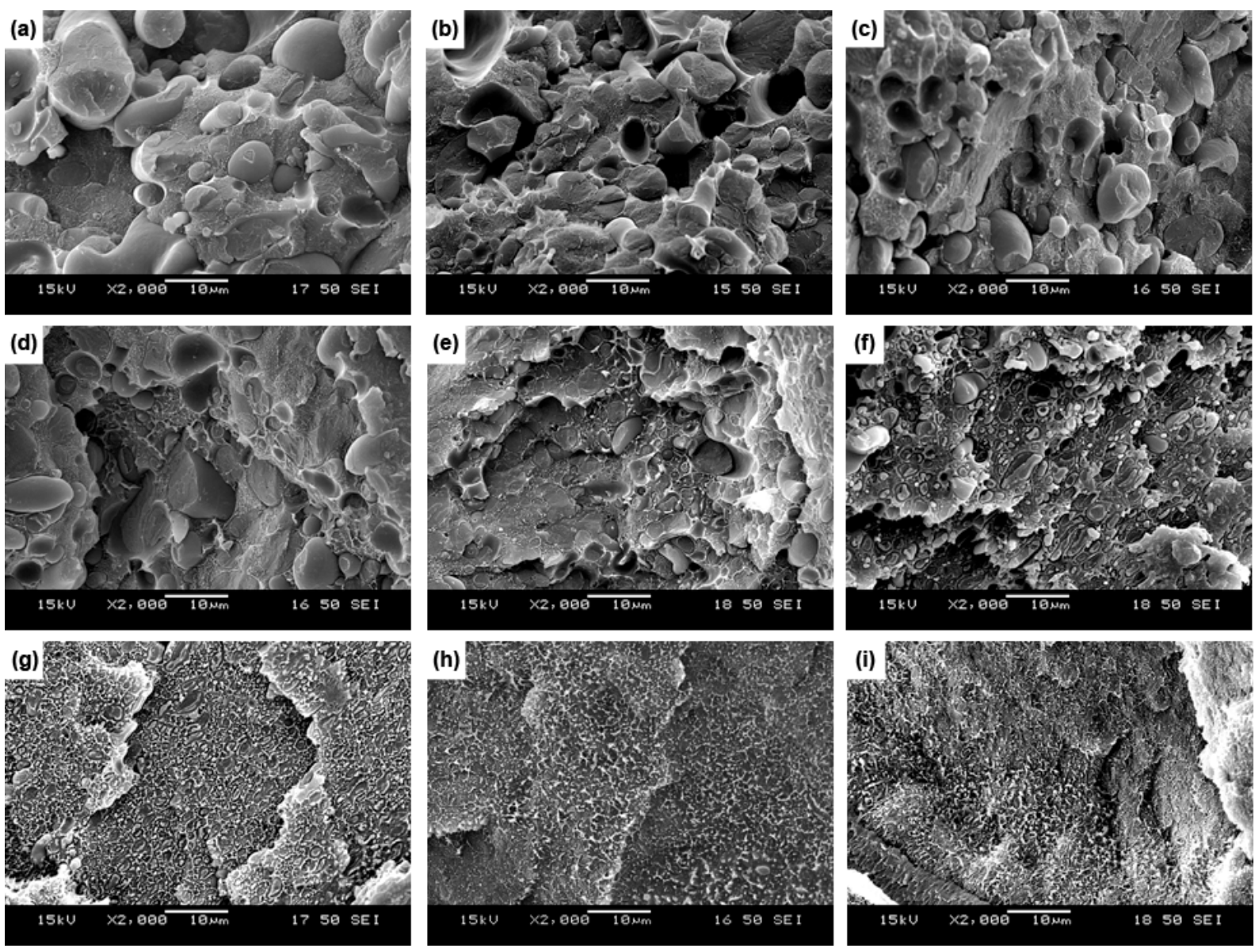

Fig. 2. Fracture surface of 50/50 PS/HDPE with different SEBS-g-MA-content, after injection moulding: (a) 0\% SEBS-g-MA; (b) 0.125\% SEBS-g-MA; (c) 0.25\% SEBS-g-MA; (d) 0.5\% SEBS-g-MA; (e) 1\% SEBS-g-MA; (f) $2 \%$ SEBS-g-MA; (g) 4\% SEBS-g-MA; (h) $6 \%$ SEBSg-MA; (i) $10 \%$ SEBS-g-MA 


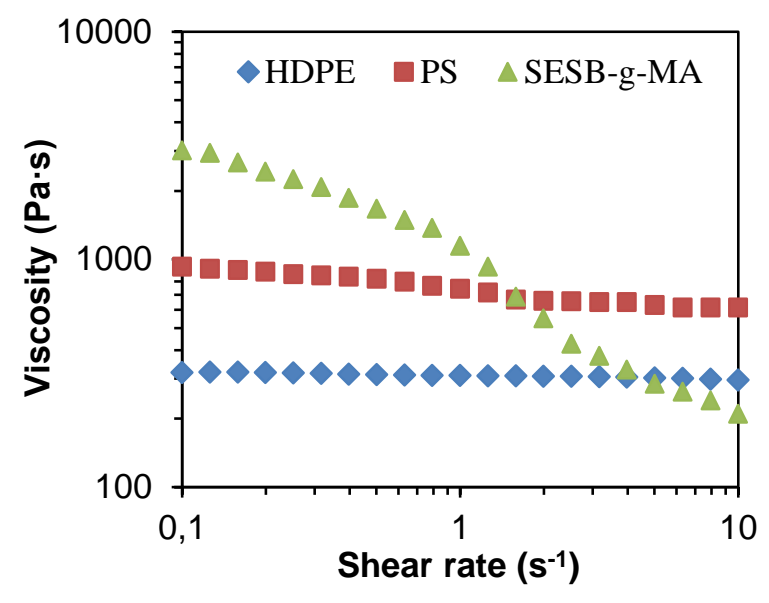

Fig. 3. Viscosity of PS, HDPE and SEBS-g-MA as a function of shear rate $\left(255^{\circ} \mathrm{C}\right)$ 


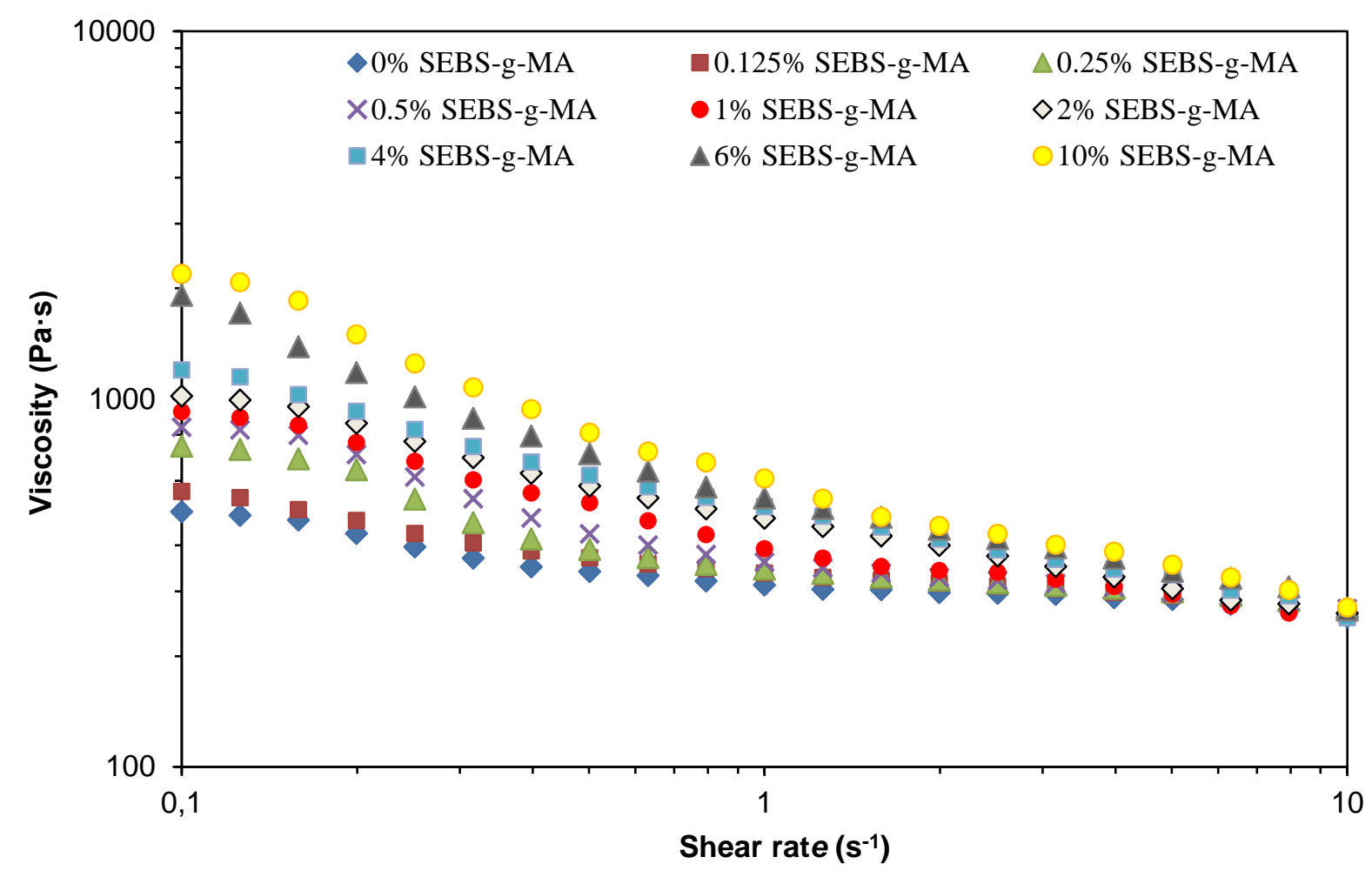

Fig. 4. Viscosity of 50/50 PS/HDPE blends with different SEBS-g-MA content: ( $\diamond)$ 0\% SEBSg-MA, ( $\bullet$ ) 0.125\% SEBS-g-MA, ( $\triangle$ ) 0.25\% SEBS-g-MA, (X) 0.5\% SEBS-g-MA (•) $1 \%$

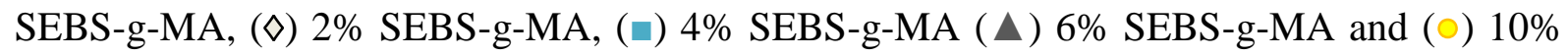
SEBS-g-MA, as a function of shear rate $\left(255^{\circ} \mathrm{C}\right)$ 


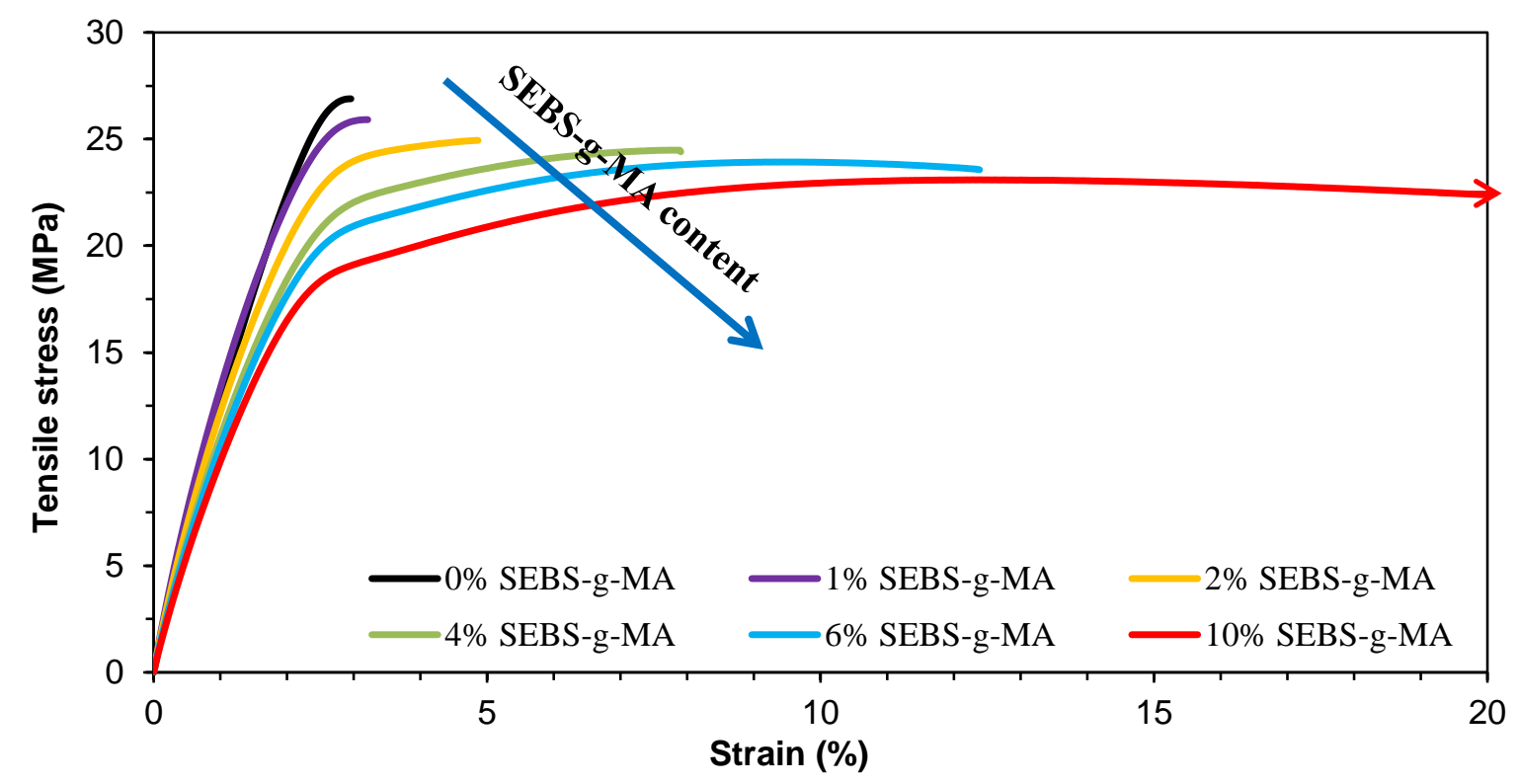

Fig. 5. The stress-strain curves of 50/50 PS/HDPE with different SEBS-g-MA content 

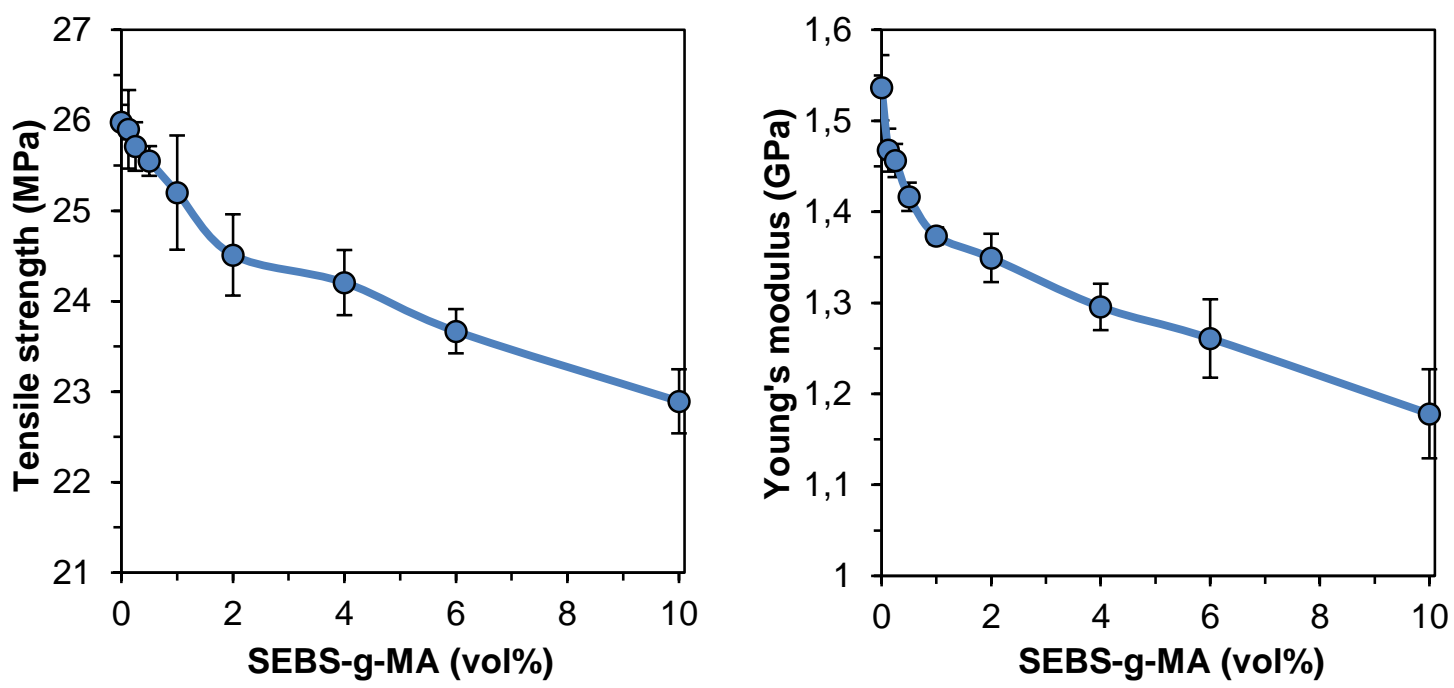

Fig. 6. (a) Tensile strength and (b) Young's modulus of 50/50 PS/HDPE blends as a function of SEBS-g-MA content 


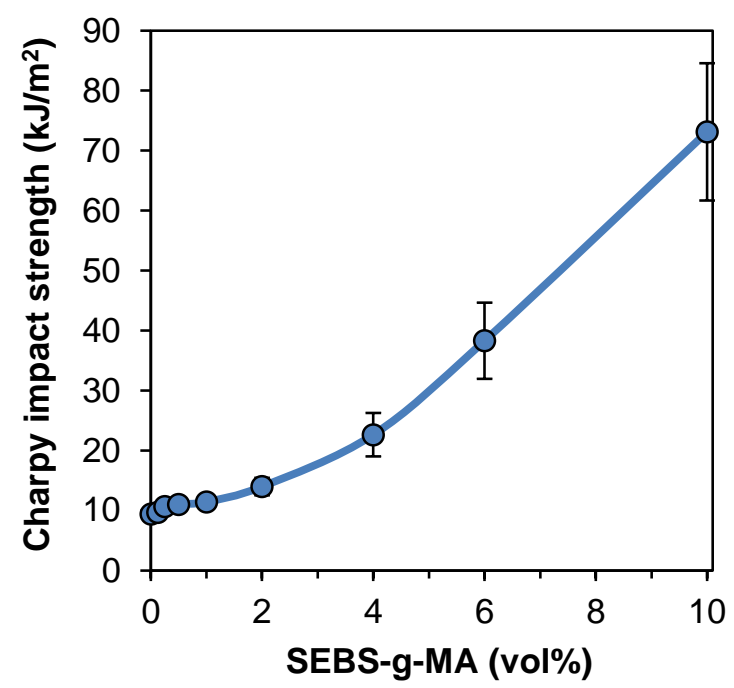

Fig. 7. Charpy impact strength of unnotched 50/50 PS/HDPE blends, as a function of SEBS-gMA content 

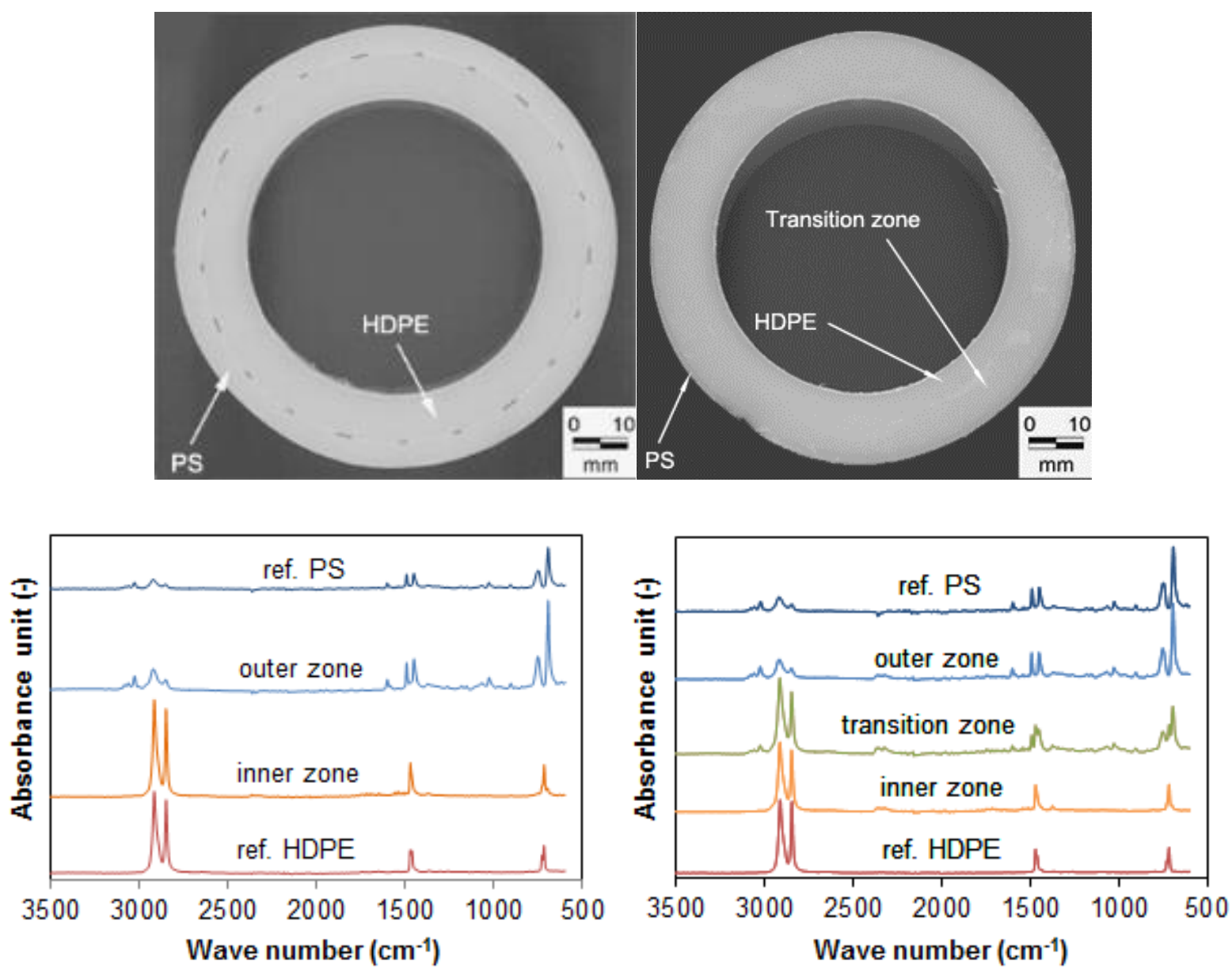

Fig. 8. Separating results of 50/50 PS/HDPE blend without and with 0.5\% SEBS-g-MA: (a) separated disc with two pure zones, where the dashed line shows the sharp transition zone between PS and HDPE; (b) FTIR spectra of the reference PS and HDPE materials, compared with the samples from the inner and outer zones from disc without SEBS-g-MA; (c) separated disc with transition zones between PS and HDPE; (d) FTIR spectra of the reference PS and HDPE materials, compared with the samples from the inner, transition and outer zones from disc with $0.5 \%$ SEBS-g-MA 


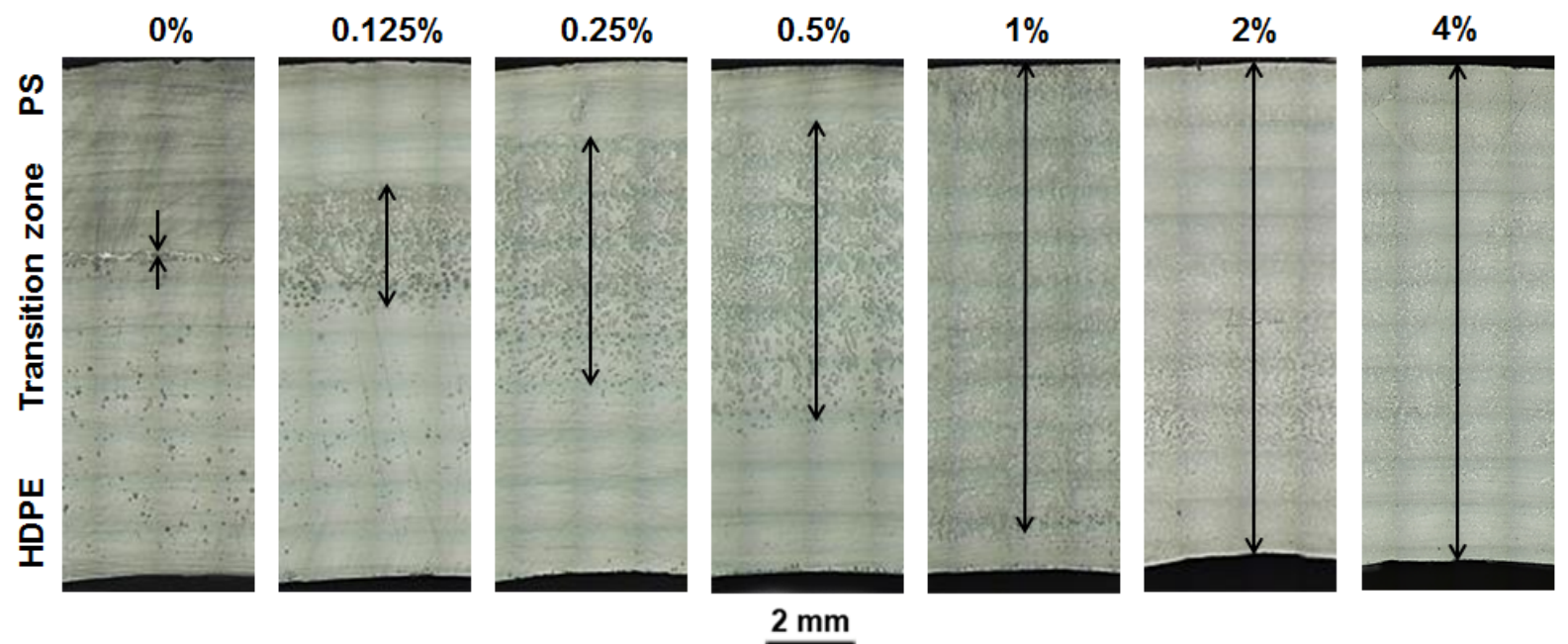

Fig. 9. Results of the separation process with the novel test method driven by centrifugal force in melted state, in 50/50 PS/HDPE blends with different SEBS-g-MA contents, where the arrow shows the thickness of the transition compatibilized zone 


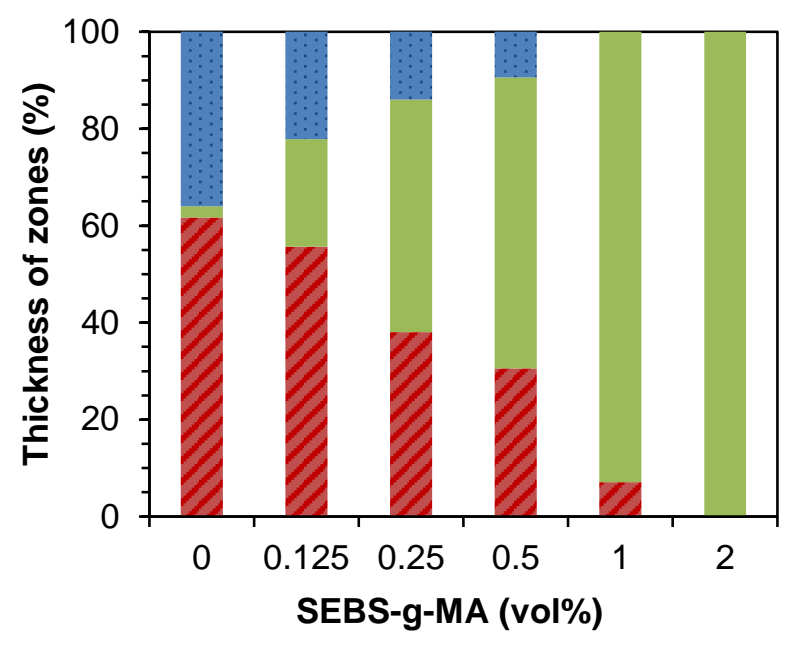

$\checkmark$ HDPE zone $\quad$ Transition zone a PS zone

Fig. 10. Thickness of PS, HDPE and the compatibilized zone as a function of SEBS-g-MA content, after the novel separation test method 


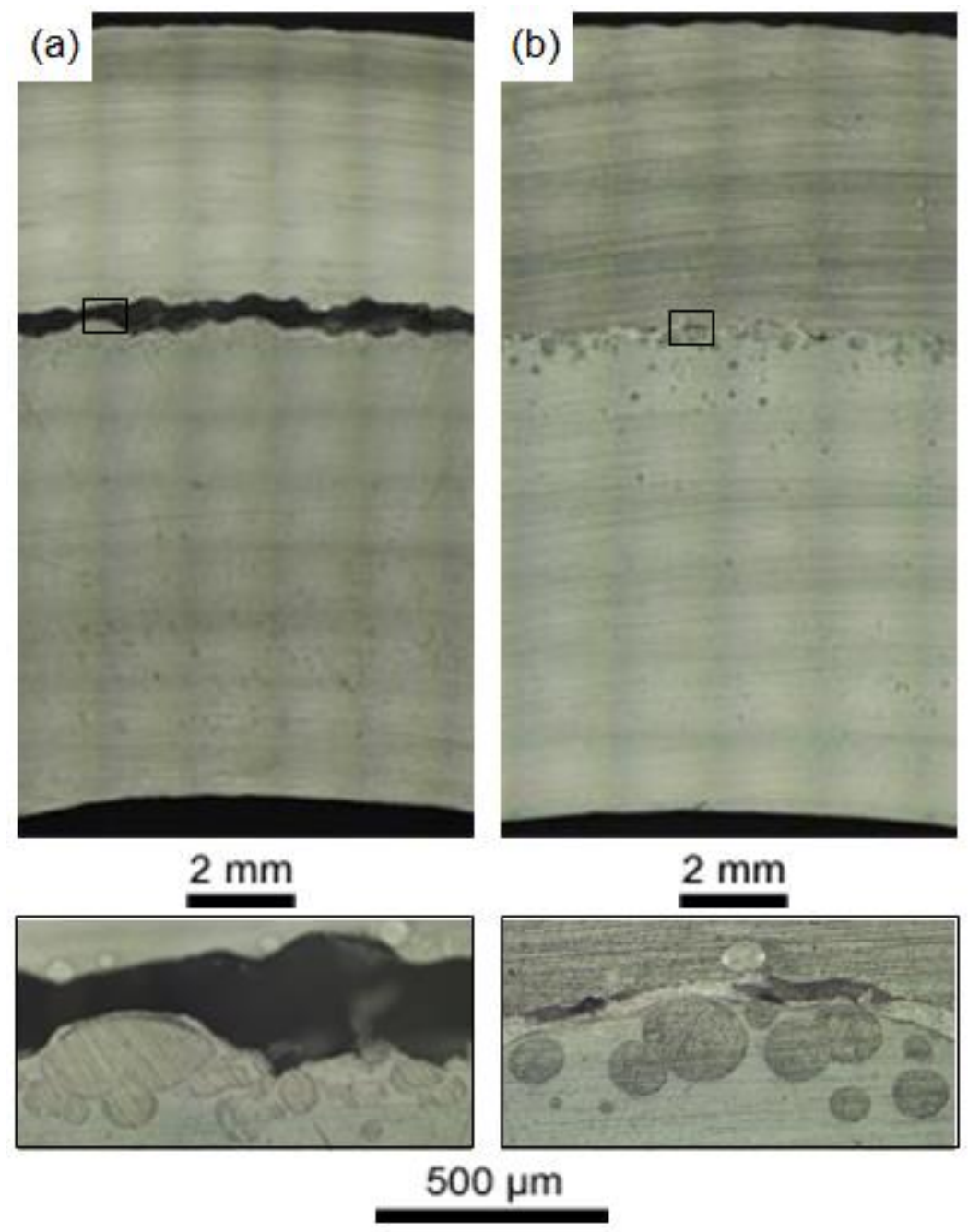

Fig. 11. Results of the separation process with the novel test method driven by centrifugal force in melted state, at 50/50 PS/HDPE blends: (a) 4 vol\% HDPE-g-MA; (b) 4 vol\% PP-g-MA 